\title{
Binary Inhibitory Anti-Rust Paint
}

\author{
Valery Trusov ${ }^{1, *}$, Rustam Khodzhaev ${ }^{1}$, Olga Shilova $^{2}$, Olga Lezova ${ }^{2}$, Oleg Zagrebelnyy ${ }^{2}$, Aleksandra Ivanova $^{2}$, Larisa \\ Krasilnikova $^{2}$, and Tatiana Belokon ${ }^{1}$ \\ ${ }^{1}$ St. Petersburg State Marine Technical University, 190121, Lotsmanskaya, 3, Saint Petersburg, Russian Federation \\ ${ }^{2}$ Institute of Silicate Chemistry of Russian Academy of Sciences, 199034, Nab. Makarova, 2, Saint Petersburg, Russian Federation
}

\begin{abstract}
A combined approach to paint was used to increase the effectiveness of anti-corrosion protection was used. In particular, passive insulating coating materials was modified with active additives. A water-soluble anodic inhibitor of atmospheric corrosion was encapsulated in a phosphate conversion coating NOTECH. As a result, the corrosion under a layer of paint primer was suppressed. It is important that phosphating does not create a layer like paint. So, such an approach is universal and compatible with most known types of paint coatings and can be combined with temporary protection (preservation). The second paint layer of the coating contained a water-oil-soluble corrosion inhibitor of the group "M", namely: N-M-1. It is adduct of natural fat vegetable acids and cyclohexylamine. The data of corrosion tests and polarization curves are presented, which confirm the high protective properties of the proposed binary inhibitory anti-rust paint.
\end{abstract}

\section{Introduction}

It is well known that phosphating is one of the best methods of chemical preparation of surfaces for applying various coatings. At the same time, a protective layer of water-insoluble phosphates is formed on the metal surface, which, in combination with layers paint provides a significant increase in the corrosion resistance of the coating. The fine-crystalline structure of the phosphate protective membrane contributes to the good absorbency of paint and thus improves their adhesion. The inert matrix of inorganic phosphates can be modified with various active additives [1, 2]. Thus, water-based rust converter NOTECH derived on phosphoric acid and acidic zinc phosphates with the addition of water-soluble inorganic inhibitors-oxidizers of the anode type is known and used in practice [3]. Due to their passivating action, the rate of submembrane corrosion under the paint layer is reduced. Phosphating, as independent protection, is rarely used, the conversion coating acts as a sublayer for the main permanent or temporary coating.

The most advanced means of enhancing anticorrosive protection are atmospheric corrosion inhibitors $[4,5,6]$

This are poorly soluble corrosion inhibitors are introduced into paint primers using various technologies, including microcapsulation $[7,8]$. The disadvantages of this technical solution are insufficient protection efficiency due to weak passivizing properties. The fact is that the modification of these inhibitors with anode-type inhibitors is impossible due to the oxidation of their main organic components by the latter. Consequently, this primer cannot be stored.

The goal of our work is to increase the effectiveness of protection by using a double inhibited coating system.
The key point of the proposed technical solution is that the anticorrosive combined paint coating consists of an inhibited phosphate layer and a paint (or preservative composition) inhibited by a water-oil-soluble inhibitor of atmospheric corrosion. This requirement is met by a cathode inhibitor of the "M" group N-M-1 [9]. It is highly soluble in most organic solvents, in other words, it is ideally combined with paint, as well as with preservative compositions based on oils and fuels, while enhancing the hydrophobizing properties of the organic matrix of paint coanting. If water penetrates under the paint layer, N-M-1 diffuses from the organic to the aqueous phase, dissolves in it with alkalizing. It effectively operates as a water preservative and complements the phosphate anodic inhibitor. The latter includes in the protection process only under a direct threat of corrosion, after penetration of water molecules to the metal surface. Thus, creates a protective combined coating of the mixed type of action.

\section{Materials and methods}

N-M-1 is a complex salt of cyclohexylamine and organic acids. This adduct is obtained by direct synthesis with a small molar excess of amine:

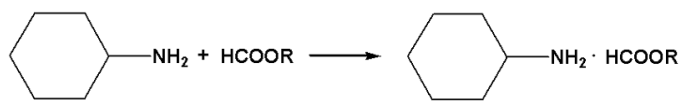

Previously used synthetic acids of $\mathrm{C}_{10^{-}}-\mathrm{C}_{13}$ and $\mathrm{C}_{10^{-}}$ $\mathrm{C}_{16}$ fractions (M-1 inhibitor) are not currently produced. $\mathrm{N}-\mathrm{M}-1$ is a modern analog that uses vegetable fat acids. Increasing the chain length to $\mathrm{C}_{18}$ has positively affected the solubility of the adduct in water, since these are mainly unsaturated acids (see Table 1).

\footnotetext{
* Corresponding author: vtrui2008@mail.ru
} 
Table 1. The approximate composition of fat acids of vegetable.

\begin{tabular}{|c|c|}
\hline Saturated fat acids, (\%) & Unsaturated fat acids, (\%) \\
\hline Myristin, 1 & Oleic, 24-40 \\
\hline Palmitic, 6-9 & Linoleic, 46-72 \\
\hline Stearic, 1,4-1,6 & Linolenic acid, 1 \\
\hline Arachin, 0,7-0,9 & \\
\hline
\end{tabular}

The proposed combined anti-rust paint system is universal, it can be either a permanent protection system or a temporary one with the conversion layer overlaid with preservatives based on oils, fuels, etc.

FMT was used as a comparison inhibitor. It is made on the basis of tall oil fatty acids modified with chlorophyll derivatives. The inhibitor is readily soluble in most organic solvents and is used in preservatives based on oils and fuels. Insoluble in water [10].

Resource-based corrosion tests of high-reliability paint coatings require significant costs and are too long. We performed the accelerate comparative assesment by determining the values of corrosion propagation from the incision. Samples (1 - The primer VL-02-1 layer, 2 - The primer VL-02-1 layer + NOTECH, 3 - The primer GF021 -1 layer + NOTECH, 4 - The primer GF-021 -1 layer with inhibitor N-M-1, $1 \%+\mathrm{NOTECH}$ ) of structural carbon steel of ordinary quality with a size of $150 \times 70 \times 2 \mathrm{~mm}$ were used for the work. Surface preparation of samples was performed by sandblasting to the degree of Sa21/2 (ISO 8501-1). VL-02-1 and GF-021 are the commercial primers. Then all samples were dried and kept indoors for 7 days. The thickness of the primer coating was 27-35 microns. On the front side of each sample, a cross-shaped incision of the coating to the metal was made with a cutter in one movement along the ruler along the diagonal of the $0.5 \mathrm{~mm}$ wide plate. After that, the samples were kept in a salt mist chamber according to GOST 9.401-91, method B (ISO 12944-6) at a temperature of $35^{\circ} \mathrm{C}$ and the concentration of sodium chloride in a continuously sprayed solution $(50 \pm 5) \mathrm{g} / \mathrm{dm}^{3}$ for 240 hours. After removing the samples from the chamber, the coating was softened with toluene and carefully removed from the samples. The value of the spread of corrosion from the incision was determined by the average value of the two lines, calculated taking into account the maximum damage every $10 \mathrm{~mm}$ of the incision line. Several coated steel plates were tested according to GOST 9.054 (in a heat and moisture chamber).

Electrochemical tests were performed using the method of potentiodynamic polarization. Potentiodynamic polarization curves were taken in a three-electrode electrochemical cell connected to a potentiostat P8S. The electrochemical cell was a glass hollow cylinder with an internal diameter of $3 \mathrm{~cm}$, pasted on a painted or unpainted steel plate. The resulting «bottom» of the cylinder was a working electrode with an area of $7.1 \mathrm{~cm}^{2}$. The auxiliary electrode - platinum wire and the reference electrode - silver wire, were located in the cylinder, not touching its «bottom». 3\% $\mathrm{NaCl}$ solution was used as the electrolyte.
Electrochemical measurements of oranosilicate coatings OS 51-03M containing corrosion inhibitors FMT, N-M-1 or applied on them as a primer, as well as OS 51-03M without inhibitors and OS 51-03M / NOTECH were carried out at potential sweep. speed $10 \mathrm{mV} / \mathrm{s}$ in the potential range from -0.9 to $+0.3 \mathrm{~V}$ with constant exposure to $3 \%$ sodium chloride solution

\section{Results}

Figure 1 shows the average results for all three parallel samples are presented.

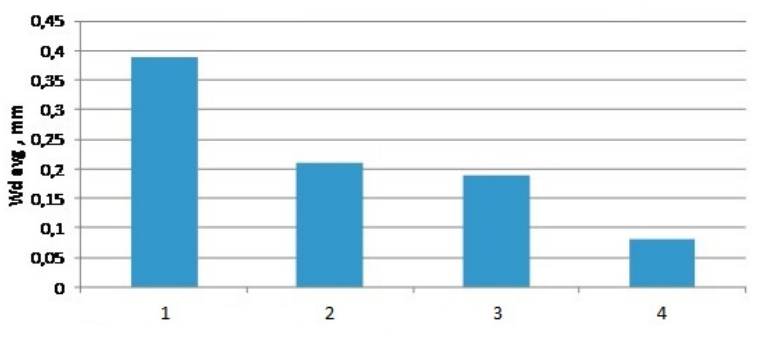

Fig. 1. Average values corrosion propagation from the incision (Wd avg.) for steel plates with coating: 1 - primer layer VL-021, 2 - primer layer VL-02-1 + NOTECH, 3 - primer layer GF021-1. + NOTECH, 4 - Primer GF-021 -1 layer with inhibitor N-M-1, 1\% + NOTECH.

Four types of coating have been studied. The worst results correspond to the selected phosphating primer of comparison VL-02 (№1). The introduction of phosphating with the NOTECH compound noticeably, on average, increases the passivating properties by 2 times both on VL-02 and on another glyptal soil GF-021 (№№2,3). Further noticeable and regular improvement is observed when adding the N-M-1 inhibitor (№4). Taking into account the experimental errors, the proposed coating system exceeds the comparison soil by at least 3 times.

The advantages of the water-oil-soluble inhibitor NM-1 in comparison with the oil-soluble inhibitor FMT are confirmed by the data in table 2 standard corrosion tests of preservative formulations with these inhibitors.

Table 2. Results of corrosion tests of solutions of oil-soluble inhibitor FMT and water-oil-soluble inhibitor N-M-1 in industrial oil I-40A according to GOST 9.054 on carbon steel in the thermal moisture chamber.

\begin{tabular}{|c|c|c|c|}
\hline \multirow{2}{*}{$\begin{array}{c}\text { Protection } \\
\text { option }\end{array}$} & \multicolumn{3}{|c|}{$\begin{array}{c}\text { Assessment of the corrosion state of steel } \\
\text { samples according to GOST 9.908, \% } \\
\text { affected surface, through the cycle }\end{array}$} \\
\cline { 2 - 4 } & 6 & 11 & 15 \\
\hline $\begin{array}{c}3 \% \text { wt. N-M-1 } \\
\text { in I-40A oil }\end{array}$ & 0.00 & 0.05 & 0.60 \\
\hline $\begin{array}{c}\text { 3\% wt. FMT } \\
\text { in I-40A oil }\end{array}$ & 0.72 & 2.13 & 6.55 \\
\hline
\end{tabular}

The obtained data of corrosion tests were compared with the electrochemical properties of the hybrid organosilicate coating OS-51-03M [11, 12] with FMT, 
N-M-1 inhibitors and NOTECH surface preparation. Some results are shown in Fig. 2.

As can be seen from the data in Fig.2, the highest corrosion current has a «pure» organosilicate coating, without an inhibitor. Whereas, the organosilicate paint OS 51-03M containing FMT inhibitors, N-M-1 or applied to it as a primer, as well as the 'OS 51$03 \mathrm{M} / \mathrm{NOTECH} / \mathrm{steel}$ ' coating differs in a significant reduction of the corrosion current to the level of sensitivity of the measuring device (for colored plates 'OS 51-03M/H-M-1/steel', 'OS 51-03M \& H-M-1/steel' and 'OS 51-03M/NOTECH/steel'. no current is detected). It was also shown that the VL-02 primer «works» less effectively in the organosilicate paints. In General, the range of effectiveness of anti-corrosion protective coatings for steel 3 will look like this: 'OS 5103M/steel'<'OS/VL-02/steel'<'OS 51-03M/FMT/steel'< 'OS 51-03M \& FMT/steel' $\approx$ 'OS 51-03M/N-M-1/steel' $\approx$ 'OS-51-03M \& N-M-1/steel' $\approx$ «OS 51-03M/ NOTECH/steel».

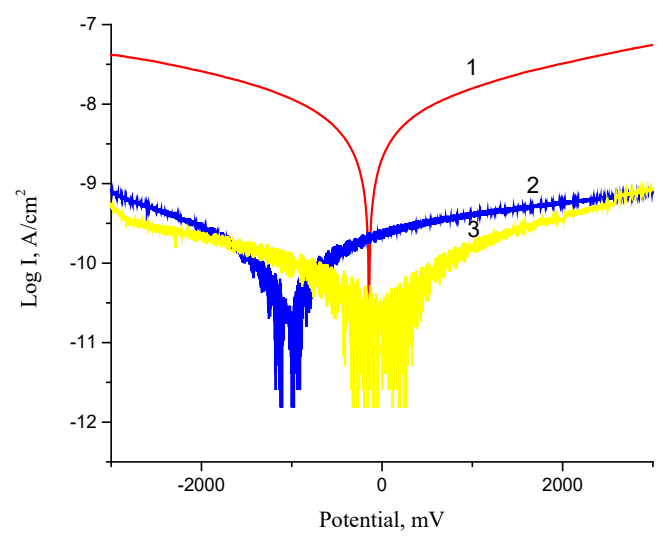

Fig. 2. Potentiodynamic polarization curves of painted steel plates after 1 month of exposure in $3 \% \mathrm{NaCl}$ solution: 1 'OS 51-03M/steel', 2 - 'OS 51-03M/FMT/steel', 3 - 'OS 5103M \& FMT/steel'.

\section{Conclusion}

The proposed binary inhibitory anti-rust paint includes an anode corrosion inhibitor in the conversion phosphate layer and a cathode inhibitor in the main primer layer of the paint or conservation coating. These coatings are combined ones of a protective action of a mixed type, which are the most effective against corrosion.

The inhibitors synergistically strengthen each other, preventing the dangerous process of hydrolysis of iron ions (with acidification) proceeding under the coating, with the development of crevice corrosion, including the key osmotic mechanism of paint destruction, etc.

The obtained data of corrosion tests are consistent with the results of electrochemical studies and confirm the high protective capabilities of the binary inhibitory anti-rust paint. The latter can be recommended for solving complex practical problems of protecting metals from atmospheric corrosion.

\section{References}

1. E.G. Rakovskaya, L.K. Yagunova, N.G. Zanko, O.A. Kudryashova. Modification of rust converters with N-containing organic compounds. Corrosion: materials, protection, 5, 26-30 (2019)

2. D.M. Bastidas, M. Criado, S. Fajardo, A.L. Iglesia, J.M.Bastidas, Corrosion inhibition mechanism of phosphates for early-age reinforced mortar in the presence of chlorides. Cement and Concrete Composites, 61, 1-6 (2015)

3. E.I. Plaskeeva, V.I. Trusov. Inhibited Composition for work in marine condition. E3S Web of Conf., 121, 02011 (2019)

4. I.L. Rosenfeld, V.P. Persiantseva, Ingibitory Atmosfernoi Korrozii (Nauka, Moscow, 1985)

5. P.B. Raja, M. Ismail, S. Ghoreishiamiri, J. Mirza, M.C. Ismail, S. Kakooei, A.A. Rahim, Pages Reviews on Corrosion Inhibitors: A Short View. Chem. Engineer. Comm., 203 (9), 1145-1156 (2016)

6. K. Tamalmani, H. Husin, Review on Corrosion Inhibitors for Oil and Gas Corrosion, Appl. Sci., 10, 3389, 2-16 (2020)

7. V.A. Golovin, A.B. Il'in, A.D. Aliev, V.A. Rabinkov, Mass transfer of phosphorus-containing corrosion inhibitors in epoxy protective coatings, Prot. Met. Phys. Chem. Surf., 55 (7), 1345-1351 (2019)

8. V.A. Golovin, S.A. Tyurina, Microencapsulation of corrosion inhibitors and active additives for anticorrosive protective polymer coatings. Int. J. Corros. Scale Inhib., 8 (2), 179-198 (2019)

9. R.S. Krymskaya, V.I. Trusov, A.I. Altsybeeva, T.M. Kuzinova, I.V. Garmashova, S.E. Bogdanova, Ingibitor korrizii H-M-1 (Corrosion inhibitor N-M1). Korrozia: Materialy, Zaschita, 9, 32-35 (2011)

10. V.I. Trusov, E.A. Bezrodnykh, E.A. Nazarov, Corrosion inhibitor with copper chlorophyll derivatives. Corrosion: materials, protection, 10, 2930 (2004)

11. V.Ya. Shevchenko, O.A. Shilova, T.A. Kochina, L.D. Barinova, O.V. Bely, Environmentally Friendly Protective Coatings for Transport, Her. Russ. Acad. Sci., 89, 279-286 (2019)

12. G.S. Buslaev, T.A., Kochina, L.N. Krasil'nikova, P.A. Milyutina, O.A. Shilova, Heat-Resistant Protective rganosilicate Coatings for Nuclear Energy. Glass Phys. Chem., 46(4), 357-359 (2020) 